\title{
PREVIDÊNCIAS DOS TRABALHADORES DOS SETORES PÚBLICO E PRIVADO E DESIGUALDADE NO BRASIL
}

\author{
Marcelo Medeiros * \\ Pedro H. G. F. Souza ${ }^{\dagger}$
}

\begin{abstract}
Resumo
O estudo examina um conjunto particular de determinantes institucionais da desigualdade, as políticas previdenciárias. Para isso, avalia a hipótese de que a diferenciação de regras quanto ao limite máximo para o valor dos benefícios nos Regimes Próprios de Previdência dos trabalhadores do setor público e o Regime Geral do setor privado responde por uma parte significativa da regressividade da previdência como um todo e contribui desproporcionalmente para a desigualdade no Brasil. A metodologia usada decompõe os fatores do coeficiente de Gini da distribuição de rendimentos familiares per capita observada na POF 2008/09. Conclui que o Estado reproduz desigualdades preexistentes por meio de direitos previdenciários diferenciados para trabalhadores dos setores público e privado. A diferenciação de regras faz com que a previdência de valores mais altos, recebida por menos de $1 \%$ da população, contribua com $4 \%$ da desigualdade total.
\end{abstract}

Palavras-chave: Desigualdade de renda; Previdência Social; Aposentadorias e Pensões; INSS; RPPS; RGPS.

\begin{abstract}
The study examines a particular set of institutional determinants of inequality, the public pensions. It tests the hypothesis that different rules regarding a maximum limit for the value of benefits in the pension subsystem of public and private sector workers make the system as a whole regressive and contribute disproportionately to inequality in Brazil. Using a factor decomposition of the Gini coefficient of the distribution of family per capita income, as measured by POF 2008/09 it concludes that the State reproduces pre-existing inequalities when it differentiates rules for public and private sector workers. Due to this differentiation of rules, the higher value of pensions of less than $1 \%$ of the population contributes to $4 \%$ of total inequality.
\end{abstract}

Keywords: Income inequality; Public Pensions; INSS; RPPS; RGPS.

JEL classification: H24; H55; I38

DOI: http ://dx.doi.org/10.1590/1413-8050/ea344

\footnotetext{
* Universidade de Brasília e Ipea. E-mail: marcelo.medeiros.cs@gmail.com

† Universidade de Brasília e Ipea. E-mail: pedrosouza@gmail.com
} 


\section{Introdução}

Se uma parte da desigualdade está relacionada a atributos das pessoas, outra parte é fortemente determinada por fatores institucionais. Entre estes estão as regras que regulam o funcionamento da previdência pública. Instituições como a previdência são particularmente importantes para o estudo da estratificação social, pois possuem uma forte tendência inercial de replicar desigualdades preexistentes. Sistemas previdenciários cujos benefícios são estabelecidos em função de contribuições anteriores potencialmente reproduzem a estrutura de distribuição de décadas passadas. Além disso, elites econômicas detêm poder político suficiente para influenciar o desenho da seguridade social em seu próprio benefício, o que faz com que a previdência possa até mesmo amplificar desigualdades prévias.

Os benefícios previdenciários de origem pública no Brasil podem ser subdivididos em dois grupos, o primeiro formado pelos benefícios dos Regimes Próprios de Previdência Social (RPPS), que atendem aos trabalhadores do setor público, incluindo militares e magistrados, e o segundo pelos benefícios do Regime Geral de Previdência Social (RPPS), que atende aos trabalhadores do setor privado. Apesar da diferenciação em função do tipo de trabalhador, ambos constituem gastos do Estado. A diferenciação de regimes poderia ser apenas uma conveniência administrativa, sem relevância para a desigualdade, mas não é. Os regimes distinguem não apenas quem beneficiam, mas a forma como distribuem benefícios. Entre outras diferenças, a previdência pública para os trabalhadores do setor privado possui um limite máximo de valor de benefício - um teto previdenciário - ao passo que esse limite não existe na previdência para trabalhadores do setor público. A limitação dos valores tem importância para a desigualdade porque, na prática, os RPPS distribuem vários benefícios acima do teto para a população de maior renda. Quando se desagregam as contribuições por tipo de regime, nota-se que a concentração dos RPPS é muito superior à do RGPS. A consequência disso é que, proporcionalmente, o regime para os trabalhadores do setor público tem muito mais influência sobre a desigualdade que o regime para os trabalhadores do setor privado.

O objetivo deste artigo é explicar por que os rendimentos de previdência dos regimes próprios dos funcionários público (RPPS) contribuem tanto para a desigualdade de renda no Brasil, quando comparados aos benefícios RGPS. Ou seja, trata-se de explicar quais as consequências de tais regras diferenciadas sobre a desigualdade brasileira. Os regimes de previdência são examinados separadamente, distinguindo-se em cada um deles a incidência e a concentração dos benefícios. Operacionalmente, a hipótese testada é a de que não são os benefícios cujos valores estão situados entre os limites vigentes para o setor privado, mas os benefícios mais altos do setor público, os que mais contribuem para a concentração da previdência no país e, consequentemente, para a desigualdade. Na prática, porém, a desigualdade pode ser resultado da combinação dessas duas alternativas. A desigualdade de renda é entendida como a desigualdade na distribuição dos rendimentos familiares per capita, conforme os dados da Pesquisa de Orçamentos Familiares (POF) de 2008/09, e é medida pelo coeficiente de Gini dessa distribuição.

Os resultados do estudo não se limitam à identificação de componentes e estimação de seus efeitos sobre a desigualdade. Esses resultados contribuem para julgar em que medida a convergência de regras entre os dois regimes 
previdenciários tem efeitos equitativos. Esse debate tem sido impulsionado por motivos fiscais e discussões sobre igualdade de direitos. Ao abordar os efeitos da diferenciação de regras sobre desigualdade de renda este estudo acrescenta uma dimensão ao debate, a da justiça distributiva.

A importância do estudo de uma previdência altamente concentrada não deve ser subestimada. Benefícios previdenciários contribuem para a formação de elites no Brasil e há evidências de que o comportamento dessas elites no tempo é fundamental para se entender a dinâmica da desigualdade em vários países (Alvaredo 2010, Atkinson 2003, 2010, Medeiros 2005, Piketty \& Saez 2006, Roine \& Waldenström 2008, Székely \& Hilgert 2000). Além disso, quando as instituições previdenciárias são incorporadas na análise da desigualdade total, torna-se mais evidente que essa desigualdade não resulta apenas de uma distribuição diferenciada de fatores e atributos pessoais mas, também, de escolhas sociais que não revertem ou até mesmo amplificam essa distribuição primária diferenciada, um argumento que recentemente tem sido sustentado por Milanovic e por Atkinson, entre outros (Atkinson 2003, Milanovic 1994).

A dimensão distributiva da previdência é especialmente importante porque tanto o RGPS quanto os RPPS são regimes de repartição. Se, por um lado, a previdência brasileira, em contrapartida a um regime de capitalização, promove redistribuição entre gerações, por outro cabe ao Estado transferir recursos fiscais para cobrir eventuais diferenças entre os pagamentos e as contribuições arrecadadas. Isso tem ocorrido sistematicamente e em volume considerável, especialmente para a previdência do funcionalismo público: em 2010, a necessidade de financiamento gerada pelos 23 milhões de benefícios do RGPS atingiu 1,2\% do PIB, enquanto os cerca de 3,3 milhões de benefícios pagos pelos RPPS demandaram mais de $2 \%$ do PIB daquele ano.

A contribuição da previdência para a desigualdade foi analisada em vários países da Europa e América do Norte. Há certa divergência nos achados dos estudos que trataram do tema, os quais dependem da metodologia utilizada. Quando os efeitos sobre a desigualdade são calculados usando-se o método das decomposições sequenciais (sequential accounting decomposition), isto é, simulações contrafactuais de supressão simples, as pesquisas tendem a concluir que a previdência tem efeitos igualitários na distribuição de renda (Brown \& Prus 2006, Caminada \& Goudswaard 2001, Coronado et al. 2011, Feldstein \& Liebman 2002, Goudswaard \& Caminada 2010, Jenkins 1995, Klazar \& Slintáková 2012, Pedraza et al. 2009, Wang et al. 2012).

No entanto, a metodologia de supressão simples é questionável, pois seus resultados não só criam uma situação completamente irrealista (um mundo que permanece constante depois que desaparece por completo a previdência, ou seja, assumem a renda zero como contrafactual), como variam demasiadamente em função da sequência de supressão adotada. Por outro lado, a medida da contribuição da previdência para a desigualdade que usa o método de decomposição de fatores (factor decomposition analysis) normalmente chega à conclusão de que os benefícios previdenciários são neutros ou até mesmo regressivos nesses países (Wang et al. 2012). Assim, nos termos da metodologia comparável à usada em nosso estudo, a previdência na América do Norte e na Europa tende a ser neutra ou levemente regressiva, a depender das configurações institucionais de cada sistema de seguridade.

Na America Latina, as evidências são de que os benefícios previdenciários são concentrados nos mais ricos. Calculados por decomposição de fatores os 
coeficientes de concentração previdenciários são impressionantemente elevados. Em alguns países, porém, a contribuição da previdência para a desigualdade não chega a patamares extremos pelo simples fato de a incidência da proteção ser relativamente baixa e, com isso, a participação da previdência na renda total ser limitada (Esquivel 2011, Lavado 2007, Soares et al. 2009).

No Brasil, existem pesquisas sobre aspectos distributivos da previdência que indicam que as aposentadorias e pensões reduzem a pobreza entre idosos, em particular as aposentadorias rurais (Beltrão et al. 2005), e, ao menos no que diz respeito ao RGPS, são progressivas do ponto de vista das desigualdades regionais (Caetano 2008, Rocha \& Caetano 2008). O efeito das aposentadorias e pensões sobre a desigualdade de rendimentos familiares per capita, no entanto, é levemente regressivo, ou seja, a previdência, como um todo, contribui para aumentar a desigualdade (Hoffmann 2003, 2009). Entre 1981 e 2001, os níveis de concentração das rendas previdenciárias são altos e estáveis, mas o aumento da participação dos benefícios previdenciários na renda das famílias fez crescer seu peso na desigualdade até pelo menos 2001 (Ferreira 2006). Estudos de períodos mais recentes argumentam que, a partir de 2001, uma leve desconcentração desses benefícios fez a previdência contribuir para a queda da desigualdade total observada no país (Barros et al. 2007, Hoffmann 2005a,b, 2009, Soares 2006).

A contribuição para a desigualdade específica dos benefícios previdenciários acima do teto foi objeto de análise recente. Rangel (2011) tem como foco os resultados de alterações no teto previdenciário e por isso não diferencia os regimes RGPS e RPPS abaixo do teto e não considera o efeito dos tributos previdenciários. Encontra níveis muito altos de concentração dos rendimentos acima do teto, mas sustenta que a imposição de um teto não traria mudanças expressivas na desigualdade de renda total, principalmente devido ao fato de o volume de rendimentos acima do teto ser proporcionalmente pequeno, se comparado a outras fontes, como os rendimentos do trabalho (Rangel 2011).

Este estudo distingue-se dos anteriores por dois aspectos principais. Primeiro, por sua ênfase na diferenciação de regras fundamentais entre os dois regimes e nos impactos da implementação dessas regras. Dentre todos os levantamentos de dados disponíveis, apenas a POF 2008/09 permite a identificação precisa de cada regime. Segundo, por analisar também efeitos de redistribuição na previdência, isto é, tratando-a em termos líquidos ao descontarem-se contribuições previdenciárias e outros tributos das rendas das famílias.

Vale ainda destacar que, como os RPPS e o RGPS são políticas públicas, a análise realizada aqui implica um exame da contribuição direta da ação estatal para a desigualdade no país. Nesse sentido, a discussão do artigo não se restringe à previdência. Em termos mais gerais, nossa análise põe em destaque como os elevados níveis de desigualdade observados no Brasil são determinados por ações de uma instituição como o Estado, cujo mandato constitucional, ao menos no que diz respeito à seguridade social, deveria ser igualitarista, isto é, deveria reverter desigualdades preexistentes.

A previdência social faz parte do conjunto mais amplo de políticas de seguridade social e a discussão do assunto com frequência remete ao debate sobre o papel desejado para essas políticas. Em termos normativos é possível, em um polo, atribuir à previdência a função de um seguro, cujo objetivo deve ser a compensação proporcional às contribuições realizadas previamente; no outro polo, é possível também atribuir à previdência função de uma política de redistribuição cujo objetivo é minimizar a desigualdade. No meio existe 
uma grande quantidade de combinações possíveis, representando diferentes escolhas políticas (Diamond 1977).

Sem dúvida, as expectativas em relação ao papel distributivo da previdência são um elemento importante no desenho de políticas sociais. Não existe, por sinal, uma expectativa única ou uma função intrínseca da previdência na redução (ou não) da desigualdade. Na verdade, essas posições expressam juízos de valor. Todavia, as conclusões relevantes de nosso estudo independem desses juízos. Os níveis de concentração dos rendimentos previdenciários empiricamente observados são os mesmos, sejam quais forem os objetivos que se desejem para a previdência.

É evidente, porém, que a simples escolha da desigualdade como objeto de estudo e o uso de medidas compatíveis com o princípio de Pigou-Dalton, como é o caso do coeficiente de Gini e dos coeficientes de concentração, denotam uma normatividade tácita. As funções de bem-estar implícitas nessas medidas têm natureza igualitarista, isto é, permitem a conclusão de que, tudo mais constante, maior igualdade implicaria maior nível de bem-estar para um determinado nível agregado de riqueza ou benefícios. Ao usar essas medidas, automaticamente, endossamos essa perspectiva. Porém, como os cálculos de nosso estudo independem de posições políticas sobre quais devam ser as funções da previdência social, preferimos não tratar do assunto no texto. Seguramente uma discussão séria do tema está muito além do escopo do artigo.

\section{Metodologia}

A estimativa das contribuições dos rendimentos de previdência dos regimes próprios dos funcionários públicos (RPPS) e do diferencial causado pela inexistência de um limite máximo de valor de benefício ou teto previdenciário nos RPPS foi feita por meio de uma decomposição de fatores do coeficiente de Gini da distribuição da renda familiar per capita da população brasileira observada nos dados da POF 2008/09 do Instituto Brasileiro de Geografia e Estatística (IBGE), cuja cobertura amostral é representativa de todo o Brasil. Como a POF 2008/09 usa um período de referência para a captação de informações sobre rendimentos de 12 meses, os dados utilizados correspondem à média mensal de valores deflacionados a reais de janeiro de 2009 e anualizados. Rendas não monetárias não foram computadas. O método da decomposição de fatores também é conhecido como decomposição da desigualdade por fontes de rendimento.

Nosso interesse é sobre a distribuição de rendimentos em um momento específico do tempo. Por esta razão, utilizamos renda corrente, como é praxe na literatura sobre desigualdade. Isto difere da prática de parte da literatura sobre previdência. Como o objetivo dessa literatura com frequência é medir os efeitos distributivos entre gerações, é comum o uso de alguma estimativa aproximada de renda permanente, apesar das críticas que podem ser realizadas (Diamond 1977). Embora este não seja nosso escopo, vale notar que é possível que o uso de medidas de renda permanente levasse a conclusões distintas das nossas.

Para a decomposição a renda das famílias foi dividida inicialmente em três fatores ou fontes de rendimentos: (i) benefícios previdenciários do RGPS; (ii) benefícios dos RPPS; e (iii) todas as demais rendas não previdenciárias, que incluem, por exemplo, os rendimentos do trabalho, aluguéis, doações, remu- 
neração de aplicações de capital, benefícios assistenciais etc. A POF identifica separadamente esses e diversos outros rendimentos, mas, como o coeficiente de Gini é aditivamente decomponível por fatores, tratá-los de forma agregada não afeta os resultados. Os benefícios do RPPS foram subdivididos em dois fatores: (a) benefícios do RPPS abaixo do teto, incluindo aqui a fração abaixo do teto de benefícios cujo valor final ultrapassasse o teto; e (b) a fração dos benefícios RPPS acima do teto, isto é, o benefício RPPS total menos o valor do teto. A contribuição do fator "fração dos benefícios RPPS acima do teto" corresponde, por definição, à contribuição da diferença entre regras previdenciárias de limite máximo de benefício existente entre o RGPS e os RPPS para a desigualdade total. Essa diferença é um dos elementos de debate na agenda política da convergência dos regimes.

Os rendimentos oriundos da previdência complementar foram incluídos entre "todas as demais rendas não previdenciárias", embora em alguns casos eles também sejam subsidiados por recursos de algumas fundações públicas ou autarquias. A razão para isso é que não é possível saber se os rendimentos declarados resultam de fundos de pensão patrocinados por órgãos com presença estatal. De todo modo, a previdência privada tem volume pequeno na POF e sua forma de classificação não deve afetar substantivamente os resultados.

Para examinar a qualidade dos dados da POF, comparamos os resultados obtidos com aqueles observados em registros administrativos. Os resultados dessa comparação são apresentados na Tabela A.1 do apêndice. Há uma convergência razoável entre os valores da POF e os de registros administrativos. Os valores totais de transferências na POF correspondem a 91\% dos constantes em registros administrativos enquanto os totais de contribuições correspondem a $88 \%$. A maior discrepância observada entre a POF e os registros administrativos ocorre nas transferências do RPPS, a uma razão de $70 \%$. Os rendimentos do RPPS são concentrados, tanto porque não possuem teto previdenciário como porque refletem contribuições de salários mais altos do que a da média dos trabalhadores. Logo, a tendência é que a contribuição relativa para a desigualdade dos rendimentos provenientes do RPPS seja ainda maior do que a estimada aqui, possivelmente reforçando algumas das conclusões do estudo.

Note-se que é comum haver divergências entre os resultados de inquéritos domiciliares amostrais e registros administrativos. Diga-se de passagem, é fato conhecido que não há coincidência total entre as diferentes fontes de registros administrativos brasileiros, havendo divergência entre as informações provenientes do Fluxo de Caixa da Previdência e as provenientes dos Anuários Estatísticos da Previdência Social (AEPS), provavelmente em função de diferenças de natureza contábil relacionadas ao pagamento de decisões judiciais, pagamentos atrasados e outros. A comparação apresentada na Tabela A.1 em parte baseia-se em dados dos AEPS, não só porque estes tendem a refletir os recebimentos regulares das famílias que são o principal objeto de nosso estudo como, também, porque evitariam uma inflação da contribuição dos rendimentos do RPPS para a desigualdade que pode ser circunstancial.

Os tributos diretos pagos pelas famílias foram divididos em três categorias, (i) contribuições para o RGPS, (ii) contribuições para os RPPS e (iii) outros tributos, que inclui todos os impostos diretos - como o imposto de renda mas não contabiliza a tributação indireta. As contribuições previdenciárias dos trabalhadores ativos seguiram a própria classificação da POF, mas as dos 
aposentados e pensionistas precisaram ser imputadas como $11 \%$ sobre a parcela dos rendimentos acima de R $\$ 3038$, o teto do RGPS em janeiro de 2009 (data de referência da POF). Vale observar que, como só se levou em conta a contribuição direta dos trabalhadores, mas não a das empresas e de outras fontes, o total transferido pela previdência é muito maior do que o arrecadado. Assim, para o caso do RGPS, por exemplo, enquanto os dados administrativos indicam que a soma dos benefícios previdenciários para 2009 foi 24\% maior do que a arrecadação líquida (Ministério da Previdência Social 2010), na POF os benefícios são $633 \%$ maiores do que as contribuições. Isso, no entanto, não afeta os resultados deste estudo.

A distribuição de benefícios da previdência social é marcada por grande diversidade. Cada regime de previdência possui tipos ou categorias de benefícios cujo caráter varia bastante. O quadro torna-se ainda mais complexo porque parte dos benefícios da assistência social é gerenciada pela máquina administrativa previdenciária. Em função disso, benefícios de caráter previdenciário, como as aposentadorias por tempo de contribuição, aposentadorias por invalidez, auxílios acidentários e auxílios-doença, com frequência são associados a políticas assistenciais como o Benefício de Prestação Continuada (BPC). Adicionalmente, por se tratar de regimes de repartição, a distribuição dos benefícios previdenciários é marcada por uma série de subsídios cruzados, um piso e um teto, de modo que o valor de alguns benefícios é parcial ou totalmente independente de um histórico contributivo anterior. Para realizar as decomposições de fatores (ou fontes de rendimento) reunimos os diversos tipos de aposentadorias e pensões em uma categoria ampla, previdência social, mas mantivemos a separação da previdência em relação a outros benefícios associáveis à seguridade social, como os benefícios da assistência (BPC e Bolsa Familia) e os benefícios de seguro desemprego e saques dos fundos de garantia por tempo de serviço.

A etapa seguinte foi a decomposição do Gini em função da contribuição de seus fatores (Kakwani, 1980). Para isso foram calculados o coeficiente de concentração $\left(C_{f}\right)$ de cada fator e a participação relativa de cada fator nos rendimentos totais $\left(\phi_{f}\right)$. A contribuição de cada fator para a desigualdade total $\left(S_{f}\right)$ é determinada pelo produto desses dois parâmetros, ou seja:

$$
S_{f}=C_{f} \cdot \phi_{f}
$$

A desigualdade total, medida pelo coeficiente de Gini, corresponde à soma das contribuições de cada fator. Para cada fonte de renda $f$, a contribuição marginal relativa para o Gini de uma variação proporcional de $e$, com $e$ tendendo a zero, é dada por:

$$
\frac{\partial G / \partial e_{f}}{G}=\frac{C_{f} \cdot \phi_{f}}{G}-\phi_{f}
$$

Ou seja, pela diferença entre a contribuição relativa da fonte $f$ para o Gini e sua participação na renda total (Lerman \& Yitzhaki 1985, Stark et al. 1986). Grosso modo, a contribuição marginal pode ser interpretada como a variação percentual do Gini resultante de um aumento proporcional de 1\% na renda do fator $f$. Naturalmente, a soma das contribuições marginais relativas é igual a zero.

Do ponto de vista causal, a decisão de trabalhar depende, entre outros fatores, da capacidade laboral e da renda previdenciária. Como inativos podem 
acumular renda do trabalho e da previdência e, até certa idade, ainda possuem capacidade laboral, por vezes as rendas previdenciárias são recebidas simultaneamente com rendimentos do trabalho, o que tende a tornar sua concentração mais alta. Como nosso objetivo é medir a concentração da previdência, independentemente dos motivos que a determinam, o efeito que o nível de renda previdenciária tem sobre a participação do mercado de trabalho não afeta diretamente nossos resultados, mas ainda assim merece ser notado.

\section{Resultados e discussão}

O foco de grande parte dos estudos sobre previdência no Brasil recai sobre seus aspectos fiscais e sua sustentabilidade de longo prazo. Em termos gerais, estudos sobre o custo total do sistema mostram que, em comparações internacionais, os gastos previdenciários brasileiros estão entre os mais elevados, mesmo quando são tomados em conta composição demográfica, regras de idade mínima, renda média da população, alíquotas de contribuição e outros fatores, o que significa que há no Brasil uma excelente proteção previdenciária para quem tem acesso a ela, mas a um custo fiscal alto. O conjunto das aposentadorias e pensões compõe mais da metade dos gastos sociais e representa uma fração grande da renda das famílias — quase um quinto da renda pessoal total. A importância da previdência nessa renda vem crescendo pelo menos desde meados da década de 1980 e a tendência é que esse crescimento se mantenha, em decorrência do envelhecimento da população (Caetano 2006, Caetano \& Miranda 2007, Camarano \& Kanso 2007, Ferreira 2006, Rangel et al. 2009).

Uma característica do sistema previdenciário brasileiro é a multiplicidade de regimes desde a origem do sistema, na década de 1920. Historicamente, no entanto, há uma nítida tendência de uniformização de regras e inclusão previdenciária. Na década de 1960, por exemplo, começam a ser tomadas medidas para a inclusão dos trabalhadores rurais na seguridade social, e em 1971 é criado o Programa de Assistência ao Trabalhador Rural (Prorural), de caráter previdenciário, posteriormente incorporado ao Sistema Nacional de Previdência Social (Sinpas). A Constituição de 1988 permitiu o acesso universal à previdência social, o que passa a ser feito com a criação de regimes especiais, regulamentados por meio de legislação ordinária a partir de 1991. As duas décadas seguintes são marcadas por uma série de ajustes legislativos e medidas administrativas cujo objetivo foi melhorar a cobertura previdenciária existente e aumentar a proteção previdenciária de uma série de grupos de trabalhadores que não estava adequadamente protegida.

A Constituição também estabelece patamares mínimos de benefício. Do ponto de vista distributivo, são particularmente importantes a instituição das aposentadorias rurais e, paralelamente, a vinculação do piso previdenciário ao salário mínimo, o que fez com que os valores de boa parte dos benefícios sejam parcial ou totalmente independentes de contribuições anteriores. Três emendas constitucionais (EC) posteriores também instituem regras com efeitos distributivos importantes. A primeira, em 1998 (EC 20), legisla sobre idade e períodos mínimos de contribuição. Um de seus objetivos era corrigir distorções introduzidas no sistema depois que a lei que instituiu o Regime Jurídico Único (RJU), em 1990, transformou em funcionários públicos servidores que antes haviam sido contratados no regime da Consolidação das Leis do Trabalho (CLT) e, portanto, não contribuíam para previdência pública, além 
de conter regras que permitiam a um servidor se aposentar com menos de 40 anos de idade. A segunda, em 2003 (EC 41), trata de matéria semelhante, aumentando os períodos de contribuição mínimos no serviço público e modificando a base de cálculo dos benefícios do último cargo ocupado para a média dos 80 maiores salários. A terceira, em 2005 (EC 47), não só visa assegurar paridade plena entre servidores ativos e aposentados, o que vincula automaticamente a política previdenciária à salarial, como também aumenta a inclusão previdenciária especial com alíquotas e vigências menores, como nos casos de proteção às trabalhadoras domésticas no âmbito da própria residência. A implementação eficaz desta última emenda depende, no entanto, da definição de legislação ordinária.

Apesar das modificações legislativas, o Brasil segue tendo dois regimes previdenciários funcionando de forma diferenciada. A uniformização dentro do RGPS e dos RPPS está avançada, mas a convergência entre os regimes, contudo, ainda será tema da agenda política por muito tempo: a própria Constituição Federal de 1988 consagrou um tratamento muito mais generoso às aposentadorias e pensões dos funcionários públicos.

A convergência está na pauta política desde meados da década de 1990, tendo sido discutida durante o governo do presidente Cardoso e incluída no programa de governo do presidente Lula (Marques \& Euzéby 2005, Melo \& Anastasia 2005). Desde a Constituição, tanto o RGPS quanto os RPPS passaram por extensas reformas. As alterações introduzidas pelas emendas constitucionais e leis infraconstitucionais mencionadas fizeram avançar o nivelamento dos regimes: as aposentadorias e pensões do setor público, por exemplo, passaram a ser devidamente caracterizadas como um regime previdenciário de cunho contributivo, com regras uniformes para os entes da federação.

Em 2012 foi sancionada a lei 12.618, que coloca um teto equivalente ao dos trabalhadores do setor privado para os benefícios dos futuros servidores e também para os atuais servidores que aderirem ao novo regime. A adesão dos atuais servidores ao novo regime é voluntária e não é vantajosa, na prática significando que no curto prazo nada substantivo é alterado no panorama distributivo da previdência para os trabalhadores do setor público brasileiro. Portanto, a imensa disparidade de regras entre os regimes provavelmente continuará sendo relevante por anos. Isso se explica por dois motivos: em primeiro lugar, todas as reformas aprovadas incidirão de fato apenas sobre os servidores contratados depois de sua aprovação e, principalmente, em quase todos os casos foram criadas generosas regras de transição para os servidores ativos. Logo, vantagens como a paridade com os servidores ativos e a inexistência de um teto como o do RGPS ainda estarão presentes no sistema por bastante tempo.

$\mathrm{O}$ segundo motivo diz respeito à própria natureza das reformas: por um lado, também o RGPS foi alterado, por exemplo, com a instituição do fator previdenciário, que equivale a um redutor aplicado aos aposentados por tempo de contribuição relativamente jovens; por outro, a própria criação da previdência complementar do setor público - precondição para a imposição do teto ao funcionalismo - prevê que o Estado deve subsidiar pelo menos parte das contribuições voluntárias dos servidores (Silveira et al. 2011).

O fato é que, sem maiores mudanças, hoje e nas próximas décadas não existirá um regime previdenciário único, mas uma série de regimes e sub-regimes com regras diferenciadas e, portanto, impactos distintos sobre a desigualdade. Convivem no sistema previdenciário sub-regimes com efeitos muito regres- 
sivos e outros bastante progressivos. É por isso que diferenciar os tipos de previdência é importante. A Tabela 1 apresenta a composição por fatores dos rendimentos familiares per capita da população como um todo e das pessoas que vivem em famílias nas quais pelo menos um dos membros recebe rendimentos ou paga contribuições de cada tipo. Essa tabela identifica as transferências diretas líquidas do Estado para as famílias sob cada regime (Regimes Próprios do funcionalismo e Regime Geral), descontando, para isso, as contribuições pagas dos benefícios recebidos. Também subdivide os rendimentos dos RPPS em duas parcelas, aquela até o valor do teto existente no RGPS (R\$ 0 a 3038) e a acima desse valor. Finalmente, computa resultados levando em conta toda a tributação das famílias, pois parte da previdência é financiada, ainda que indiretamente, por outros tributos.

Só por suas dimensões a previdência social já teria um papel muito importante na determinação dos níveis de desigualdade brasileiros. O conjunto das rendas previdenciárias constitui uma parcela bastante grande da renda das famílias - mesmo quando descontados os tributos, inclusive as contribuições previdenciárias, essa fração ainda alcança $17 \%$ da renda total. A única fonte que supera esse valor são os rendimentos do trabalho. A incidência também é grande: aproximadamente $31 \%$ da população vive em famílias que recebem rendas da previdência.

No entanto, apesar de os dois regimes serem públicos, há uma diferença clara entre a distribuição do regime geral que atende aos trabalhadores do setor privado e a dos regimes próprios que atendem ao setor público. O RGPS beneficia uma grande quantidade de pessoas com benefícios mais baixos enquanto os RPPS beneficiam uma fração pequena da população, mas com benefícios de valor mais elevado. A proporção da população que vive em famílias nas quais pelo menos uma das pessoas é beneficiária do RGPS, $28 \%$, é muito maior do que a proporção em famílias de beneficiários dos RPPS, cerca de $4 \%$, mas os benefícios per capita nas famílias que recebem RGPS (R\$311) são quase três vezes menores do que entre famílias que recebem RPPS (R \$ 913).

A inexistência de um limite máximo para o valor dos benefícios nos regimes próprios de funcionários públicos civis, militares e magistrados explica grande parte dessa diferença. Entre as pessoas que vivem em famílias que recebem benefícios previdenciários dos RPPS, a maior parte - mais de 75\% - se beneficia com valores inferiores aos do teto do RGPS. A soma de todos esses benefícios abaixo do teto equivale a cerca de $2 \%$ da renda total das famílias. No entanto, o $1 \%$ da população que recebe benefícios acima do teto apropria-se de quase o dobro disso, cerca de $4 \%$ da renda total. Só a parcela da renda acima do valor do teto responde por aproximadamente $35 \%$ toda a renda distribuída pelos RPPS.

Além de terem grande volume, as rendas previdenciárias são concentradas, tal como já apontou a literatura sobre o tema. A Tabela 2 ilustra essa concentração ao comparar o recebimento de previdência e outras rendas e o pagamento de contribuições e tributos dos $50 \%$ mais pobres da população e os $5 \%$ mais ricos. Nela é possível observar que a fração mais rica da população contribui diretamente mais para a previdência que a fração mais pobre, mas, em contrapartida, recebe muito mais benefícios que os mais pobres. Os valores per capita recebidos pelos 5\% mais ricos ( $R$ \$ 835) são quase 27 vezes maiores que os recebidos pelos os $50 \%$ mais pobres ( $R \$ 31)$. A razão, que já é alta no RGPS, alcança níveis extremos nos RPPS, com os rendimentos previdenciários dos $5 \%$ mais ricos sendo quase 160 vezes maiores que os dos $50 \%$ 


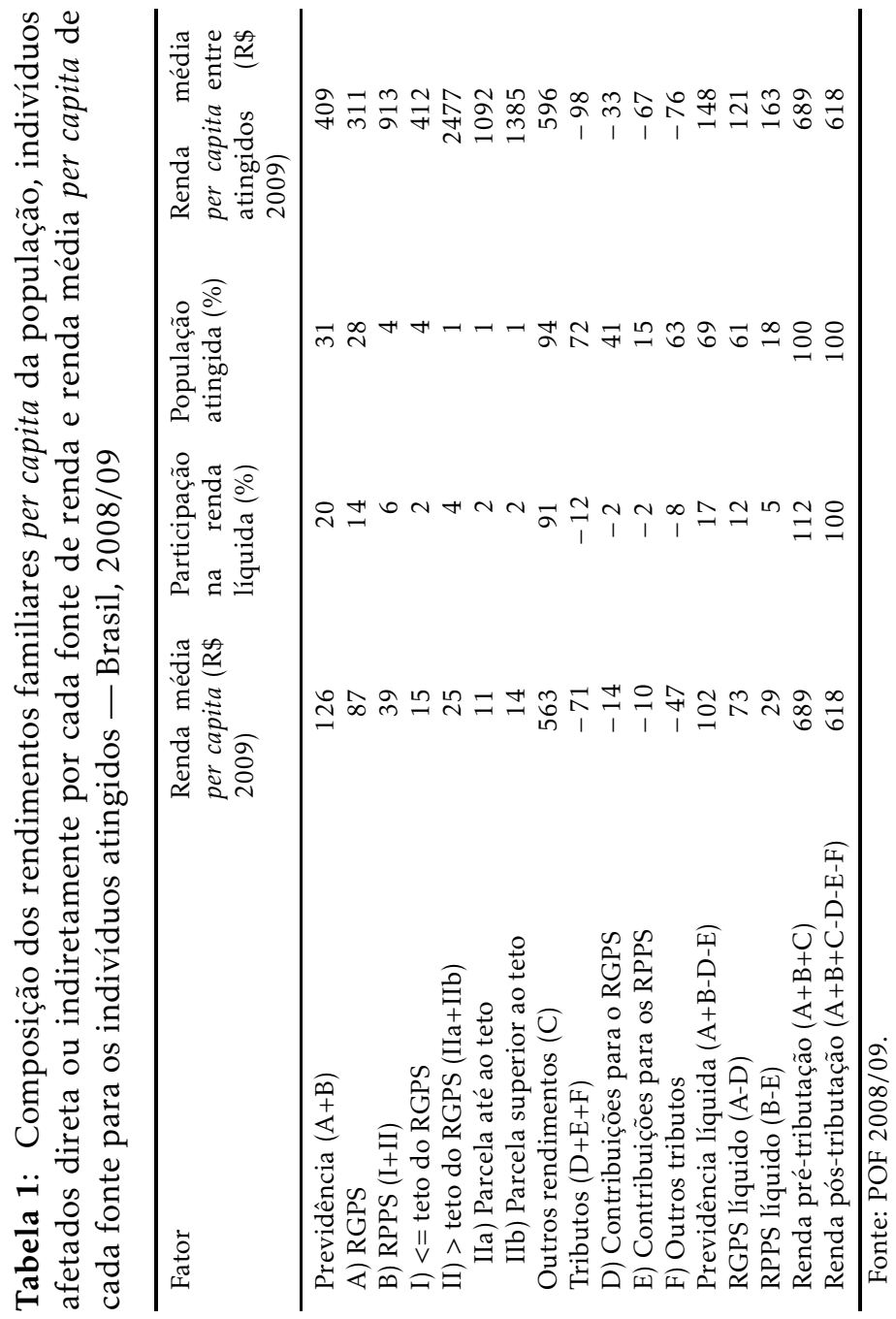


mais pobres. Já no que diz respeito à contribuição direta, no RGPS a razão entre os mais ricos e os mais pobres é de 17 vezes e nos RPPS de 94 vezes, valores altos, mas inferiores aos encontrados na distribuição de benefícios.

Esses resultados, aparentemente, divergem dos obtidos por Afonso \& Fernandes (2005), cuja conclusão é de que, embora a distribuição das rendas previdenciárias seja regressiva, dentro do sistema previdenciário existe redistribuição no longo prazo, com os contribuintes mais ricos subsidiando os beneficiários mais pobres ao longo do tempo. No entanto, não é possível uma comparação direta dos dois estudos. Sem dados de painel é muito difícil avaliar com exatidão a magnitude de efeitos redistributivos de longo prazo da previdência, pois, por um lado, o financiamento dos sistemas previdenciários não se restringe à contribuição de seus segurados e o pagamento de impostos diretos e, por outro, o regime de contribuição é de repartição, não sendo possível identificar precisamente o quanto de um benefício recebido é repagamento de suas contribuições anteriores.

Tabela 2: Composição dos rendimentos familiares per capita dos 50\% mais pobres e dos 5\% mais ricos - Brasil, 2008/9

\begin{tabular}{|c|c|c|c|c|}
\hline \multirow[t]{2}{*}{ Fator } & \multicolumn{2}{|c|}{$50 \%$ mais pobres } & \multicolumn{2}{|c|}{$5 \%$ mais ricos } \\
\hline & $\begin{array}{l}\text { Renda média } \\
\text { per capita } R \$ \\
2009\end{array}$ & $\begin{array}{l}\text { Participação } \\
\text { na renda } \\
\text { líquida }(\%)\end{array}$ & $\begin{array}{l}\text { Renda média } \\
\text { per capita } R \$ \\
2009\end{array}$ & $\begin{array}{l}\text { Participação } \\
\text { na renda } \\
\text { líquida }(\%)\end{array}$ \\
\hline Previdência $(A+B)$ & 31 & 18 & 835 & 22 \\
\hline A) RGPS & 28 & 16 & 356 & 9 \\
\hline B) RPPS (I+II) & 3 & 2 & 479 & 13 \\
\hline I) $<=$ teto do RGPS & 2 & 1 & 72 & 2 \\
\hline II) $>$ teto do RGPS (IIa+IIb) & 0 & 0 & 406 & 11 \\
\hline IIa) Parcela igual ao teto & 0 & 0 & 159 & 4 \\
\hline IIb) Parcela superior ao teto & 0 & 0 & 247 & 6 \\
\hline Outros rendimentos $(\mathrm{C})$ & 154 & 89 & 3601 & 95 \\
\hline Tributos $(\mathrm{D}+\mathrm{E}+\mathrm{F})$ & -12 & -7 & -636 & -17 \\
\hline D) Contribuições para o RGPS & -4 & -2 & -68 & -2 \\
\hline E) Contribuições para os RPPS & -1 & -1 & -94 & -2 \\
\hline F) Outros tributos & -7 & -4 & -475 & -12 \\
\hline $\begin{array}{l}\text { Previdência líquida (A+B-D- } \\
\text { E) }\end{array}$ & 26 & 15 & 674 & 18 \\
\hline RGPS líquido (A-D) & 25 & 14 & 289 & 8 \\
\hline RPPS líquido (B-E) & 2 & 1 & 385 & 10 \\
\hline $\begin{array}{ll}\text { Renda } & \text { pré-tributação } \\
(\mathrm{A}+\mathrm{B}+\mathrm{C}) & \end{array}$ & 185 & 107 & 4436 & 117 \\
\hline $\begin{array}{l}\text { Renda pós-tributação }(\mathrm{A}+\mathrm{B}+\mathrm{C}- \\
\mathrm{D}-\mathrm{E}-\mathrm{F})\end{array}$ & 173 & 100 & 3800 & 100 \\
\hline $\begin{array}{l}\text { Fonte: POF 2008-9. } \\
\text { Nota: "renda pós-tributação" } \\
\text { contribuições previdenciárias } \\
\text { referem-se aos valores dos ber } \\
\text { contribuicões previdenciárias }\end{array}$ & $\begin{array}{l}\text { efere-s } \\
\text { os im } \\
\text { efícios }\end{array}$ & $\begin{array}{l}\text { ento total } \\
\text { os. "RGPS } \\
\text { rios depois }\end{array}$ & $\begin{array}{l}\text { opulação, desc } \\
\text { uido" e "PPS Lí } \\
\text { descontadas as }\end{array}$ & $\begin{array}{l}\text { contadas as } \\
\text { íquido" }\end{array}$ \\
\hline
\end{tabular}

Os esforços de contribuição são aproximadamente os mesmos entre mais ricos e mais pobres e se estabelecem em torno de $1 \%$ e $2 \%$ da renda de cada grupo, independente do regime previdenciário. Porém, ao que tudo indica há um viés de classe entre os dois sistemas. As rendas do RGPS são importantes para os mais pobres, ao passo que as dos RPPS têm importância maior entre os mais ricos. Elas chegam a representar $16 \%$ da renda posterior à tributação das famílias entre os $50 \%$ mais pobres e $9 \%$ entre as mais ricas. No caso dos RPPS 
as posições praticamente se invertem, $2 \%$ e $13 \%$, respectivamente. Chama a atenção o fato de que nos RPPS a parcela superior ao que seria o teto do RGPS tem entre os $5 \%$ mais ricos um volume maior do que todos os benefícios dos RPPS abaixo desse teto equivalente.

As rendas previdenciárias são todas concentradas mas, ainda assim, as diferenças entre o RGPS e os RPPS são muito grandes, como mostra a Tabela 3. Apesar de concentrada, a previdência do regime geral (RGPS) tem coeficiente de concentração inferior ao valor do coeficiente de Gini, ou seja, é progressiva. Já a previdência dos regimes próprios (RPPS) é muito regressiva, com um coeficiente de concentração quase 1,5 vezes superior ao Gini. Essa regressividade tão alta se dá pela combinação de uma já regressiva previdência cujos benefícios se encontram abaixo do teto a uma previdência de benefícios que ultrapassam o teto que é ainda mais regressiva. A concentração destes últimos, 0,939, é duas vezes maior que a do RGPS. Para se ter uma noção do que significa esse valor, basta lembrar que um aumento de apenas 10\% nessa concentração praticamente equivaleria a dar todos os benefícios acima do teto à pessoa mais rica do país.

A previdência dos regimes próprios que beneficiam os trabalhadores do setor público é uma previdência para a população mais rica do país. Não há outro fator na composição da desigualdade brasileira tão concentrado quanto as rendas dos RPPS. Sua concentração elevada é resultado da combinação de valores e incidência concentradores, com benefícios altos sendo pagos aos estratos mais ricos da população. A maior parte dessa concentração deve-se aos benefícios cujo valor é mais alto que o teto vigente no regime para os trabalhadores do setor privado. Embora faça parte da renda familiar de menos de $1 \%$ da população, a previdência dos regimes próprios dos funcionários público (RPPS) acima do teto contribui com cerca de $7 \%$ de toda a desigualdade no Brasil. Só a parcela RPPS superior ao teto já contribui com $4 \%$ de toda a desigualdade. Mesmo descontadas as contribuições para a previdência $(-2 \%$ da desigualdade) os rendimentos dos RPPS ainda seriam um fator com desproporcional contribuição para a desigualdade.

A coluna de contribuições marginais da Tabela 3 apresenta uma estimativa do que ocorreria com a desigualdade caso o peso de um determinado fator na renda total fosse aumentado, sem, no entanto, modificar a concentração desse fator. Colocando em outras palavras, equivale à elasticidade da desigualdade a um aumento do peso relativo do fator. Nessa coluna observa-se que o fator com pior impacto sobre a desigualdade é a previdência dos regimes próprios dos funcinários público (RPPS), fato que não deve ser subestimado diante da tendência de crescimento da previdência como um todo destacada pela literatura especializada (Caetano 2006, Camarano \& Kanso 2007). A um aumento de $1 \%$ no volume das rendas do RPPS corresponderia um crescimento de 0,029\% da desigualdade. Para efeitos de comparação, ao mesmo aumento de $1 \%$ do RGPS corresponderia uma queda de $0,022 \%$ na desigualdade. Mesmo uma elevação de $1 \%$ em todos os tributos, e não apenas nas contribuições previdenciárias, não seria suficiente para contrabalançar o crescimento de $1 \%$ dos RPPS.

A grande regressividade dos RPPS tem um forte componente inercial e, portanto, pode-se esperar alguma melhora do seu perfil distributivo no futuro. No entanto, como as reformas são muito recentes e sacramentaram regras de transição muito lentas, a ação concentradora dos RPPS deve perdurar ainda por um longo período. Além disso, como o próprio Estado foi elevado 


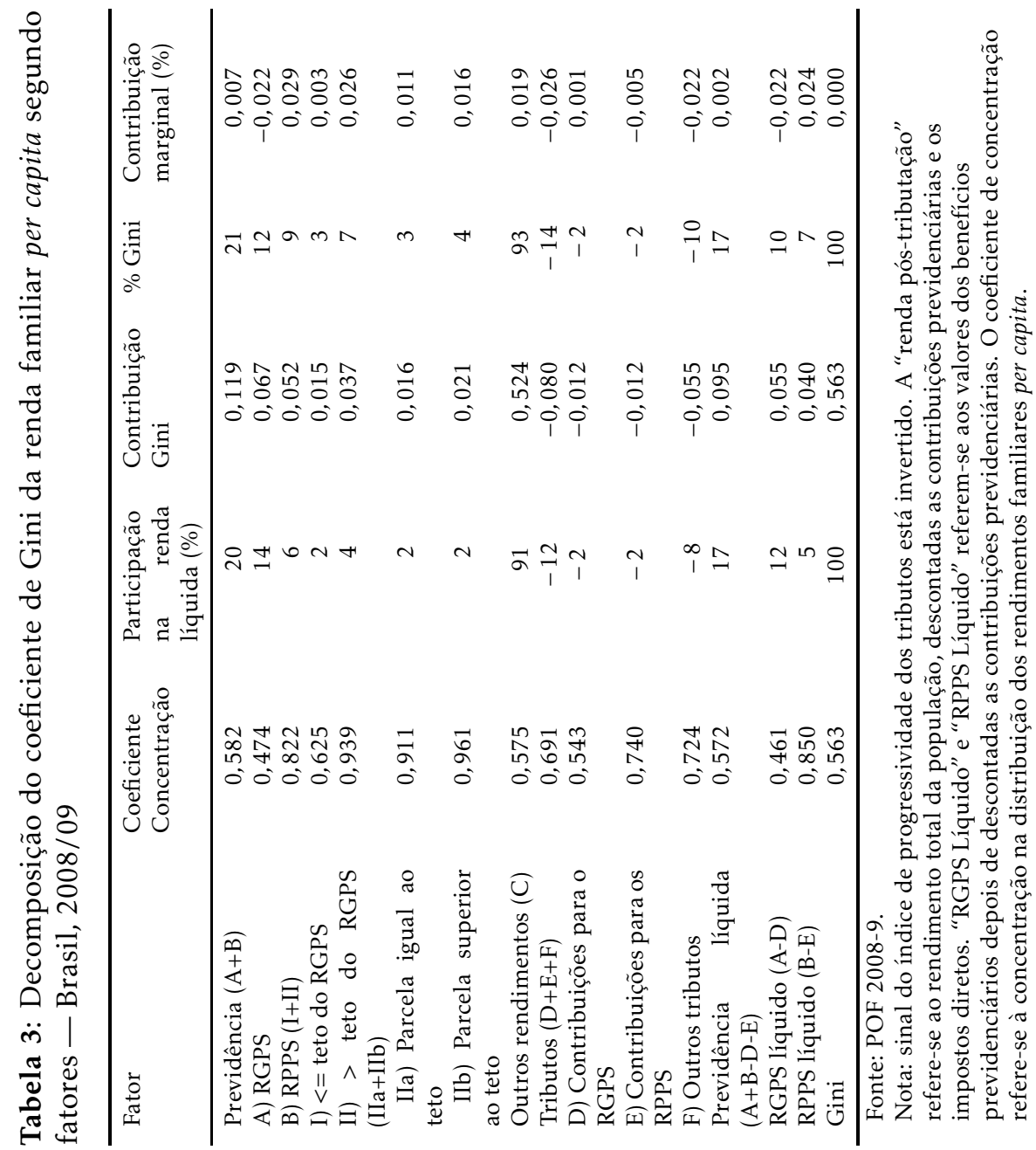


à posição de co-financiador da previdência complementar do setor público, a convergência com o RGPS permanecerá incompleta e mesmo no longo prazo a regressividade dos RPPS deve continuar, ainda que em menor grau. Finalmente, há que considerar que é mais provável uma harmonização lenta dos dois regimes do que sua unificação completa e rápida, pois uma unificação tenderia a reduzir a arrecadação do RPPS à medida que as contribuições sobre os benefícios acima do teto do RGPS deixariam de existir (Caetano 2006).

É importante notar ainda que a previdência pode ser entendida ainda sob uma ótica mais ampla, a de um conflito distributivo que determina os padrões de política fiscal. Nesse caso o efeito concentrador da previdência não se resumiria à concentração dos benefícios previdenciários, mas incluiria a combinação de distribuição em nível alto e concentrada com arrecadação progressiva, mas em nível baixo. Quando a arrecadação de contribuições é inferior às necessidades de financiamento da previdência, parte do gasto previdenciário precisa ser coberta com tributos ou endividamento. Esses tributos, em sua maioria, são indiretos e sem progressividade relevante, como os tributos sobre combustíveis; o endividamento, por sua vez, gera não só despesas regressivas com juros e amortizações como, também, pressão por emissão de moeda, cuja inflação resultante tende a ser regressiva dada a menor capacidade de proteção dos mais pobres. Em uma perspectiva de longo prazo, inflação e desigualdade frequentemente apresentam correlação positiva (Albanesi 2007). Com os dados e as ferramentas de que dispomos, no entanto, não é possível medir esse efeito concentrador combinado.

\section{Conclusão}

Uma análise da estratificação social no Brasil é incompleta se não considerar a distribuição de benefícios previdenciários. A previdência pública contribui para uma fração considerável da renda de quase um terço das famílias brasileiras e contribui com cerca de um quinto da desigualdade total de renda no país. A tendência é que sua importância cresça ao longo do tempo, acompanhando a ampliação da proteção social e o envelhecimento da população.

O sistema previdenciário, no entanto, não é homogêneo. Não existe um regime previdenciário único, mas sim a combinação de uma série de regimes e sub-regimes com características próprias e impactos diferenciados sobre a desigualdade. Uma primeira divisão do sistema previdenciário distingue o regime geral da previdência social (RGPS), que atende aos trabalhadores do setor privado, e os regimes próprios (RPPS), previdência dos trabalhadores do setor público. A população que está em famílias que recebem alguma renda previdenciária é, majoritariamente, beneficiária do RGPS.

Embora os dois regimes sejam públicos, há uma diferença nas características distributivas de ambos. O RGPS transfere benefícios de valores mais baixos, mas alcança uma grande quantidade de pessoas em diversas camadas sociais, ao passo que os RPPS têm benefícios mais altos, beneficia muito menos gente e atinge, primariamente, a população das classes mais elevadas. As contribuições previdenciárias suavizam, mas não são capazes de reverter esse viés distributivo a favor dos mais ricos. Entre ricos e pobres a proporção da renda das famílias dispendida com contribuições previdenciárias é semelhante e corresponde a uma fração pequena do total. As diferenças entre regimes são sintetizadas por seus coeficientes de concentração, ambos sendo 
muito concentrados, mas apresentando níveis extremamente altos no caso dos RPPS. Como resultado, a previdência pública como um todo é levemente regressiva, isto é, contribui para aumentar a desigualdade.

Há uma tendência de convergência entre os dois regimes, mas, sem maiores mudanças nas legislações atuais, uma unificação dificilmente ocorrerá nas próximas décadas. Com o passar do tempo o componente inercial da regressividade dos RPPS deve diminuir, e seu perfil distributivo melhorar. Porém, como até o momento as reformas que favorecem a convergência são recentes e estabelecem regras de transição lentas, essa regressividade deve permanecer por longo período.

Uma parte importante do impacto sobre a desigualdade diferenciado entre os dois regimes é explicada pela inexistência de um limite máximo para o valor dos benefícios na previdência dos trabalhadores do setor público, tal como existe no regime geral da previdência social. O coeficiente de concentração da distribuição dos benefícios dos RPPS que ultrapassam o teto é quase o dobro do observado em todo o RGPS. Embora menos de 1\% da população viva em famílias em que ao menos uma pessoa recebe benefícios RPPS acima do valor do teto vigente no RGPS, esses benefícios mais altos têm um peso desproporcional na desigualdade, contribuindo com $4 \%$ da desigualdade total.

Não é possível afirmar que uma convergência de regras entre regimes previdenciários que levasse à imposição de um limite superior de benefícios também para os regimes dos trabalhadores do setor público resultaria em uma redução dos mesmos $4 \%$ da desigualdade, pois isso dependeria tanto de como as contribuições para a previdência fossem modificadas quanto de como esses recursos fossem realocados. A tendência, no entanto, é que a equiparação de regras de limitação de benefícios entre o RPPS e o RGPS tenha efeitos igualitaristas.

Em termos mais gerais os resultados obtidos complementam estudos cujo enfoque são os efeitos de atributos pessoais sobre a desigualdade, ao mostrar que uma parte importante dessa desigualdade é determinada também por fatores institucionais. Direitos previdenciários diferenciados estabelecidos no passado têm e terão efeitos relevantes sobre a desigualdade ao longo de décadas. Seja qual for a origem dessa diferenciação, o fato é que políticas públicas como a previdência, cujos benefícios atuais são calculados em função de contribuições passadas, tendem a reproduzir vários tipos de desigualdades preexistentes. Há, portanto, políticas de larga escala por meio das quais o Estado amplifica as desigualdades no Brasil.

\section{Agradecimentos}

Agradecimentos: várias pessoas colaboraram com a elaboração deste texto. Agradecimento especial é devido a Marcelo Abi-Ramia Caetano, do Ipea. Pedro H. G. F. Souza agradece o apoio da UC Berkeley durante parte da realização do estudo. Marcelo Medeiros é bolsista PQ2 do CNPq.

\section{Referências Bibliográficas}

Afonso, L. E. \& Fernandes, R. (2005), 'Uma estimativa dos aspectos distributivos da previdência social no Brasil', Revista Brasileira de Economia 59(3), 295334. 
Albanesi, S. (2007), 'Inflation and inequality', Journal of Monetary Economics 54(4), 1088-1114.

Alvaredo, F. (2010), The rich in argentina over the twentieth century: 19322004, in A. B. Atkinson \& T. Piketty, eds, 'Top Incomes: A Global Perspective', Oxford University Press, Oxford, pp. 253-298.

Atkinson, A. B. (2003), 'Income inequality in oecd countries: Data and explanations', CESifo Economic Studies 49(4), 479-513.

Atkinson, A. B. (2010), Top incomes in a rapidly growing economy: Singapore, in A. B. Atkinson \& T. Piketty, eds, 'Top Incomes: A Global Perspective', Oxford University Press, Oxford, pp. 220-252.

Barros, R. P., Carvalho, M., Franco, S. \& Mendonça, R. (2007), Determinantes Imediatos da Queda da Desigualdade de Renda Brasileira, Texto para Discussão, n. 1253, Ipea, Rio de Janeiro.

Beltrão, K. I., Camarano, A. A. \& Mello, J. L. (2005), Mudanças nas Condições de vida dos Idosos Rurais Brasileiros: Resultados não-esperados dos Avanços da Seguridade Rural, Texto para Discussão, n. 1066, Ipea.

Brown, R. L. \& Prus, S. G. (2006), 'Income inequality over the later-life course: a comparative analysis of seven oecd countries', Annals of Actuarial Science 1(2), 307-317.

Caetano, M. A. (2006), Determinantes da sustentabilidade e do custo previdenciário: aspectos conceituais e comparações internacionais, Texto para Discussão, n. 1226, Ipea, Brasília.

Caetano, M. A. (2008), Previdência social e distribuição regional da renda, Texto para Discussão, n. 1318, Ipea, Brasília.

Caetano, M. A. \& Miranda, R. B. (2007), Comparativo Internacional para a Previdência Social, Texto para Discussão, n. 1302, Ipea, Brasília.

Camarano, A. A. \& Kanso, S. (2007), Previdência no Brasil: debates, dilemas e escolhas, Ipea, Rio de Janeiro, chapter Dinâmica da população brasileira e implicações para a Previdência Social.

Caminada, K. \& Goudswaard, K. (2001), 'International trends in income inequality and social policy', International Tax and Public Finance 8(4), 395-415.

Coronado, J. L., Fullerton, D. \& Glass, T. (2011), 'The progressivity of social security', The B.E. Journal of Economic Analysis E Policy 11(1), 1-45.

URL: http://works.bepress.com/don_fullerton/11

Diamond, P. A. (1977), 'A framework for social security analysis', Journal of Public Economics 8(3), 275-298.

Esquivel, G. (2011), 'The dynamics of income inequality in Mexico since NAFTA', Economía 12(1), 155-179.

Feldstein, M. \& Liebman, J. B. (2002), The Distributional Aspects of Social Security and Social Security Reform, University of Chicago Press, Chicago. 
Ferreira, C. R. (2006), 'Aposentadorias e distribuição da renda no brasil: uma nota sobre o período 1981 a 2001', Revista Brasileira de Economia 60(3), 247260.

Goudswaard, K. \& Caminada, K. (2010), 'The redistributive effect of public and private social programmes: a cross-country empirical analysis', International Social Security Review 63(1), 1-19.

Hoffmann, R. (2003), 'Aposentadorias e pensões e a desigualdade da distribuição da renda no Brasil', Econômica 5(1), 135-144.

Hoffmann, R. (2005a), 'As transferências não são a causa principal da redução da desigualdade', Econômica 7(2), 335-341.

Hoffmann, R. (2005b), 'Distribuição da renda no brasil: mudanças de 2002 para 2003 e a delimitação dos relativamente ricos', Econômica 7(1), 77-95.

Hoffmann, R. (2009), 'Desigualdade da distribuição da renda no Brasil: a contribuição de aposentadorias e pensões e de outras parcelas do rendimento domiciliar per capita', Economia e Sociedade 18(1), 213-231.

Jenkins, S. P. (1995), 'Accounting for inequality trends: Decomposition analyses for the UK, 1971-86', Economica 62(245), 29-63.

Klazar, S. \& Slintáková, B. (2012), 'How progressive is the czech pension security?', Prague Economic Papers 1(3), 309-327.

Lavado, P. (2007), Desigualdad en los programas sociales en el Perú, number 34 in 'Diagnóstico y Propuesta', CIES.

Lerman, R. I. \& Yitzhaki, S. (1985), 'Income inequality effects by income source: A new approach and applications to the united states', The Review of Economics and Statistics 67(1), 151-156.

Marques, R. M. \& Euzéby, A. (2005), 'Um regime único de aposentadoria no brasil: pontos para reflexão', Nova Economia 15(3), 11-29.

Medeiros, M. (2005), O que faz os ricos ricos? O outro lado da desigualdade brasileira, Editora Hucitec \& ANPOCS, São Paulo.

Melo, C. R. \& Anastasia, F. (2005), 'A reforma da previdência em dois tempos', Dados 48(2), 301-332.

Milanovic, B. (1994), Determinants of Cross-country Income Inequality: An "Augmented"Kuznets Hypothesis, World Bank Policy Research Working Paper, n. 1246, World Bank, Washington, DC.

Ministério da Previdência Social (2010), Regime Geral de Previdência Social: balanço do ano de 2009, Ministério da Previdência Social, Brasília.

Pedraza, P. d., Llorente, R. M. d. B. \& Rivas, L. A. (2009), 'Ageing population and spanish pension system reforms: Effects on average pensions and inequality among pensioners', Economical Analysis Working Papers 8(7), 1-24.

Piketty, T. \& Saez, E. (2006), 'The evolution of top incomes: a historical and international perspective', American Economic Review 96(2), 200-205. 
Rangel, L. (2011), Aspectos Distributivos do Regime de Previdência dos Servidores Públicos, Texto para Discussão, n. 1617, Ipea, Brasília.

Rangel, L., Vaz, F. \& Ferreira, J. (2009), 'Desigualdade na distribuição de renda: Enfoque nas aposentadorias e pensões públicas', Informe de Previdência Social, Ministério da Previdência 21(5), 2-23.

Rocha, R. R. \& Caetano, M. A. (2008), Previdência Social no Brasil: debates e desafios, Ipea, Brasília, chapter $\mathrm{O}$ sistema previdenciário brasileiro: uma avaliação de desempenho comparada.

Roine, J. \& Waldenström, D. (2008), 'The evolution of top incomes in an egalitarian society: Sweden, 1903-2004', Journal of Public Economics 92(12), 366-387.

Silveira, F. G., Mostafa, J., Caetano, M. A. \& Santos, M. P. G. (2011), Previdência dos Servidores Públicos: Reflexões em Torno da Proposta de Instituição da Previdência Complementar, Texto para Discussão, n. 1679, Ipea, Brasília.

Soares, S. (2006), 'Anáise de bem-estar e decomposição por fatores da queda na desigualdade entre 1995 e 2004', Econômica 8(1), 83-115.

Soares, S., Osorio, R. G., Soares, F. V., Medeiros, M. \& Zepeda, E. (2009), 'Conditional cash transfers in brazil, chile and mexico: Impacts upon inequality', Estudios Economicos n. ex, 207-224.

Stark, O., Taylor, J. E. \& Yitzhaki, S. (1986), 'Remittances and inequality', The Economic Journal 96(383), 722-740.

Székely, M. \& Hilgert, M. (2000), What Drives Differences in Inequality Across Countries?, IDB Working Paper, n. 369, Inter-American Development Bank.

Wang, C., Caminada, K. \& Goudswaard, K. (2012), 'The redistributive effect of social transfer programmes and taxes: a decomposition across countries', International Social Security Review 65(3), 27-48.

\section{Apêndice A Comparação entre dados previdenciários da POF 2008/09 e de registros administrativos}


Tabela A.1: Transferências e contribuições dos empregados no RGPS e nos RPPS na POF 2008/09 e nos registros administrativos (média entre 20082009)

\begin{tabular}{|c|c|c|c|}
\hline Tipo de rendimento & (1) POF 2008-2009 & $\begin{array}{l}\text { (2) Registros Ad- } \\
\text { ministrativos - } \\
\text { Média 2008-2009 }\end{array}$ & $\begin{array}{l}\text { (3) Razão POF e Re- } \\
\text { gistros Administra- } \\
\text { tivos }(\%)\end{array}$ \\
\hline \multicolumn{4}{|l|}{ RGPS } \\
\hline (a) Transferências & 197,8 & 187,1 & 106 \\
\hline $\begin{array}{l}\text { (b) Contribuições dos em- } \\
\text { pregados e afins }\end{array}$ & 31,3 & 39,4 & 79 \\
\hline \multicolumn{4}{|l|}{ RPPS } \\
\hline (c) Transferências 88,7 & 127,3 & 70 & \\
\hline $\begin{array}{l}\text { (d) Contribuições dos em- } \\
\text { pregados e afins }\end{array}$ & 22,7 & 22,2 & 102 \\
\hline \multicolumn{4}{|l|}{ Total } \\
\hline (e) Transferências $(a+c)$ & 286,5 & 314,3 & 91 \\
\hline $\begin{array}{l}\text { (f) Contribuições dos em- } \\
\text { pregados e afins }(b+d)\end{array}$ & 54,0 & 61,6 & 88 \\
\hline
\end{tabular}

Fontes: (1) microdados da Pesquisa de Orçamentos Familiares 2008-2009. (2) Ministério da Previdência Social. Anuário Estatístico da Previdência Social 2010. Brasília: MPS/Dataprev, 2010, p. 145, tabela B.3 - "Valor de benefícios emitidos, por clientela, segundo os grupos de espécies - Acumulado no ano - 2008/2010". (2b) Ministério da Previdência Social. Anuário Estatístico da Previdência Social 2010. Brasília:

MPS/Dataprev, 2010, p. 696, tabela 41.2 - "Valor mensal das receitas do INSS, segundo as principais rubricas - 2008" (soma das rubricas "Contribuição de Segurados", "Contribuição Individual de Segurados", "Contrib. Prev. do Segurado Facultativo", "Contrib. Previd. do Seg. Obrig. - Emp. Doméstico" e "Contrib. Previ. do Segurado Especial"). (3b) Ministério da Previdência Social. Anuário Estatístico da Previdência Social 2010. Brasília: MPS/Dataprev, 2010, p. 698, tabela 41.3 - "Valor mensal das receitas do INSS, segundo as principais rubricas - 2009" (soma das rubricas "Contribuição de Segurados", "Contribuição Individual de Segurados", "Contrib. Prev. do Segurado Facultativo", "Contrib. Previd. do Seg. Obrig. - Emp. Doméstico" e "Contrib. Previ. do Segurado Especial”). (2d;3d) União: Secretaria de Gestão Pública (SEGEP/MPOG). Boletim Estatístico de Pessoal, v. 17, n. 201, 2013, p. 18, tabela 1.1 "Despesa anual de pessoal da União por Poder, segundo a situação de vínculo - SIAFI". Estados e municípios: Ministério da Previdência Social. Anuário Estatístico da Previdência Social 2010. Brasília: MPS/Dataprev, 2010, p. 768, tabela 47.5 - "Resultado previdenciário dos RPPS, segundo as Grandes Regiões e Unidades da Federação 2008/2010". (2e) União: Secretaria do Tesouro Nacional. Relatório resumido da execução orçamentária do governo federal e outros demonstrativos, dezembro/2008, p. 43, Anexo $\mathrm{V}$ - "Demonstrativo das receitas e despesas previdenciárias do Regime Próprio dos Servidores Públicos". Estados e municípios: estimado como um terço da "Receita Previdenciária" encontrada Ministério da Previdência Social. Anuário Estatístico da Previdência Social 2010. Brasília: MPS/Dataprev, 2010, p. 768, tabela 47.5 - "Resultado previdenciário dos RPPS, segundo as Grandes Regiões e Unidades da Federação 2008/2010". (3e) União: Secretaria do Tesouro Nacional. Relatório resumido da execução orçamentária do governo federal e outros demonstrativos, dezembro/2009, p. 42, Anexo $\mathrm{V}$ - "Demonstrativo das receitas e despesas previdenciárias do Regime Próprio dos Servidores Públicos". Estados e municípios: estimado como um terço da "Receita Previdenciária" encontrada em Ministério da Previdência Social. Anuário Estatístico da Previdência Social 2010. Brasília: MPS/Dataprev, 2010, p. 768, tabela 47.5 — "Resultado previdenciário dos RPPS, segundo as Grandes Regiões e Unidades da Federação 2009/2011". 